TITLE:

\title{
Preparation of sodium hexatitanate photocatalysts by a flux method for photocatalytic steam reforming of methane
}

\section{$\operatorname{AUTHOR}(\mathrm{S})$ :}

Yoshida, Hisao; Mizuba, Shota; Yamamoto, Akira

\section{CITATION:}

Yoshida, Hisao ...[et al]. Preparation of sodium hexatitanate photocatalysts by a flux method for photocatalytic steam reforming of methane. Catalysis Today 2019, 334: 30-36

\section{ISSUE DATE:}

2019-08-15

URL:

http://hdl.handle.net/2433/242820

\section{RIGHT:}

(c) 2019. This manuscript version is made available under the CC-BY-NC-ND 4.0 license

http://creativecommons.org/licenses/by-nc-nd/4.0/; The full-text file will be made open to the public on 15 August 2021 in accordance with publisher's 'Terms and Conditions for Self-Archiving'; この論文は出版社版でありません。引用の際 には出版社版をご確認ご利用ください。; This is not the published version. Please cite only the published version. 
Preparation of sodium hexatitanate photocatalysts by a flux method for photocatalytic steam reforming of methane

Hisao Yoshida, ${ }^{a, b, *}$ Shota Mizuba, ${ }^{a}$ Akira Yamamoto ${ }^{a, b}$

${ }^{a}$ Graduate School of Human and Environmental Studies, Kyoto University, Kyoto 606-8501, Japan

${ }^{b}$ Elements Strategy Initiative for Catalysts and Batteries (ESICB), Kyoto University, Kyoto 615-8520, Japan

* To whom correspondence should be addressed. E-mail: yoshida.hisao.2a@kyoto-u.ac.jp

*Corresponding author:

Hisao Yoshida, Professor, Dr.

Course of Studies on Material Science

Department of Interdisciplinary Environment

Graduate School of Human and Environmental Studies

Kyoto University

Yoshida-nihonmatsu-cho, Sakyo-ku, Kyoto 606-8501, JAPAN

Phone: +81-75-753-6594

FAX: +81-75-753-2988

E-mail: yoshida.hisao.2a@kyoto-u.ac.jp

\section{Abstract}

Fine crystals of sodium hexatitanate $\left(\mathrm{Na}_{2} \mathrm{Ti}_{6} \mathrm{O}_{13}\right)$ were prepared by a flux method for photocatalytic steam reforming of methane (PSRM) to produce hydrogen. The examined parameters for the preparation in this study were the solute concentration in the molten sodium chloride salt and the cooling rate from the molten mixture. As a reference, another sample was prepared by a solid state reaction method, which corresponds the preparation without the sodium chloride flux. The prepared samples consisted of hexagonal rod-like microcrystals of monoclinic structure with various morphology, particle size, crystallite size, aspect ratio, and 
specific surface area. The solute concentration affected the length and the aspect ratio of the rod-like structure although the cooling rate did not so much. The samples were loaded with 0.05 wt\% of Rh cocatalyst nanoparticles, which was well dispersed oxide species on the surface. The Rh-loaded samples exhibited photocatalytic activity for hydrogen production in the PSRM. It was found that the photocatalytic production rate varied with the various structural parameters, especially correlated with the crystallite size of the rod-like $\mathrm{Na}_{2} \mathrm{Ti}_{6} \mathrm{O}_{13}$ fine crystals.

Keywords: Heterogeneous photocatalyst; Flux method; Photocatalytic steam reforming of methane; Hydrogen. 


\section{Introduction}

Utilization of solar energy is necessary for our sustainable society in future. To use the energy any time even at night, the conversion of the solar energy to storable chemical compounds having high chemical potential is desired. While battery as a useful device to store energy as chemical potential, many kinds of reactive chemical compounds themselves are also good energy carriers. Hydrogen is one of the storable chemical energies since it is a useful for fuel cells or hydrogen engines.

Currently, hydrogen has been produced from methane through a steam reforming of methane (SRM). Although two catalytic reactions are involved in SRM, the overall chemical equation can be shown in Eq. (1) [13].

$$
\mathrm{CH}_{4}+2 \mathrm{H}_{2} \mathrm{O} \rightarrow 4 \mathrm{H}_{2}+\mathrm{CO}_{2} \quad \Delta_{\mathrm{r}} \mathrm{G}^{\ominus}{ }_{298 \mathrm{~K}}=113.5 \mathrm{~kJ} \mathrm{~mol}^{-1}
$$

This reaction is a thermodynamically difficult endergonic reaction with a large Gibbs energy change $\left(\Delta_{\mathrm{r}} G^{\ominus}\right)$ and thus requires a large energy to proceed even in the presence of excellent catalysts.

Recently, some kinds of photocatalytic reaction systems have been widely studied to convert solar energy to hydrogen such as water splitting [4,5] and methane conversion [6-9], since photoenergy can compensate the large Gibbs energy change. We first reported that photocatalytic steam reforming of methane (PSRM) can proceed around room temperature with metal loaded photocatalysts such as Pt-loaded $\mathrm{TiO}_{2}$ photocatalyst $[10,11]$ and Pt-loaded La-doped $\mathrm{NaTaO}_{3}$ photocatalyst $[10,12]$. After that, several kinds of metal loaded photocatalysts have been reported such as Pt-loaded $\mathrm{CaTiO}_{3}$ photocatalyst $[13,14]$, Pt-loaded or Rh-loaded $\mathrm{Ga}_{2} \mathrm{O}_{3}$ photocatalysts [15-17], and Rh-loaded $\mathrm{K}_{2} \mathrm{Ti}_{6} \mathrm{O}_{13}$ photocatalyst $[18,19]$.

In these kinds of metal oxide semiconductors, the crystal defects have been considered to reduce the photocatalytic activity because they may enhance the recombination of photoexcited electron-hole pairs. To develop these kinds of photocatalysts, one of the possible strategies would be the fabrication of highly sufficient semiconductor crystals with less crystal defects. Flux method can provide fine single or poly crystals since the staring materials can react with each other in the molten flux at high temperature. It has been applied to fabricate various micro or nano-sized photocatalysts in recent years. For example, many kinds of titanate photocatalysts were reported such as $\mathrm{A}_{2} \mathrm{Ti}_{6} \mathrm{O}_{13}(\mathrm{~A}=\mathrm{Na}$ and $\mathrm{K})$ [20-24], $\mathrm{Na}_{2} \mathrm{Ti}_{3} \mathrm{O}_{7}[20], \mathrm{ATiO}_{3}(\mathrm{~A}=\mathrm{Ca}, \mathrm{Sr}$, and $\mathrm{Pb})[25-$ 28], $\mathrm{La}_{2} \mathrm{Ti}_{2} \mathrm{O}_{7}[29,30], \mathrm{CaZrTi}_{2} \mathrm{O}_{7}[31]$, and $\mathrm{AgLi}_{1 / 3} \mathrm{Ti}_{2 / 3} \mathrm{O}_{2}$ [32]. Among them, sodium hexatitanate, $\mathrm{Na}_{2} \mathrm{Ti}_{6} \mathrm{O}_{13}$, with 
a unique tunnel structure has been reported as photocatalysts for some reactions such as degradation of dye $[20,21]$, and reduction of carbon dioxide with water [22].

For the PSRM, we recently examined to prepare several Pt-loaded La-doped $\mathrm{NaTaO}_{3}$ photocatalysts by using a flux method and found that these photocatalysts exhibited higher activity than the one prepared without the flux [33], suggesting that the flux method has a potential to give active photocatalyst for the PSRM. Thus, in the present study, we prepared several sodium hexatitanate $\left(\mathrm{Na}_{2} \mathrm{Ti}_{6} \mathrm{O}_{13}\right)$ samples by a flux method in several conditions. The examined parameters for the preparation are solute concentration in the molten mixture and cooling rate from the molten mixture. As a cocatalyst, rhodium is employed, according to the previous studies of the Rh-loaded $\mathrm{Ga}_{2} \mathrm{O}_{3}$ photocatalyst [15], and the Rh-loaded $\mathrm{K}_{2} \mathrm{Ti}_{6} \mathrm{O}_{13}$ photocatalyst $[18,19]$, the latter of which implies that it can improve the photocatalytic activity of the $\mathrm{Na}_{2} \mathrm{Ti}_{6} \mathrm{O}_{13}$ photocatalyst in the PSRM.

\section{Experimental}

\subsection{Sample preparation}

Sodium hexatitanate $\left(\mathrm{Na}_{2} \mathrm{Ti}_{6} \mathrm{O}_{13}, \mathrm{NTO}\right)$ samples were synthesized by a flux method in the similar manner as reported [22]. The start materials, $\mathrm{Na}_{2} \mathrm{CO}_{3}$ (Rare metallic, 99.9\%) and $\mathrm{TiO}_{2}$ (rutile, Kojundo, 99.9\%, $2 \mu \mathrm{m}$ ), were mixed with a $\mathrm{NaCl}$ flux (Kishida, 99.5\%), whose melting points are 1124,2116 , and $1074 \mathrm{~K}$, respectively. The molar ratio of $\mathrm{Na}_{2} \mathrm{CO}_{3}$ to $\mathrm{TiO}_{2}$ was stoichiometric (1:6), and various solute concentration ( $x$ mol\% as $\left.\mathrm{Na}_{2} \mathrm{Ti}_{6} \mathrm{O}_{13}\right)$ in the molten mixture were examined, where $x$ was defined as: $x[\mathrm{~mol} \%]=100 \times\left(\right.$ amount of $\left.\mathrm{Na}_{2} \mathrm{Ti}_{6} \mathrm{O}_{13}[\mathrm{~mol}]\right) /\left(\right.$ amount of $\mathrm{Na}_{2} \mathrm{Ti}_{6} \mathrm{O}_{13}[\mathrm{~mol}]+$ amount of $\mathrm{NaCl}$ [mol]). The mixture of the starting materials and the flux in a platinum crucible loosely covered by a lid was heated at a rate of $2000 \mathrm{~K} \mathrm{~h}^{-1}$ to $1273 \mathrm{~K}$ in an electric furnace, held at this temperature for $5 \mathrm{~h}$, and then cooled at various rate $y \mathrm{~K}$ $\mathrm{h}^{-1}$ such as $-120000,-100$, and $-10 \mathrm{~K} \mathrm{~h}^{-1}$ (standard: $-100 \mathrm{~K} \mathrm{~h}^{-1}$ ) to $773 \mathrm{~K}$, followed by being naturally cooled to room temperature in the furnace. When the sample was rapidly cooled at the rate, $\mathrm{y}=-120000 \mathrm{~K} \mathrm{~h}^{-1}$, the molten mixture in the crucible around $1273 \mathrm{~K}$ was directly soaked in water. The obtained products were well washed with hot water (353 K) three times to remove the flux and then dried at $323 \mathrm{~K}$ overnight. These samples are referred to as NTO $(x, y)$, e.g., $\mathrm{NTO}(50,-100)$ and so on.

The NTO $(100,-100)$ sample was prepared without using the flux $(x=100 \%)$, which is corresponding to a solid state reaction (SSR) method. The mixture of the start materials, $\mathrm{Na}_{2} \mathrm{CO}_{3}$ and $\mathrm{TiO}_{2}$, was ground well, heated with the same rate of $2000 \mathrm{~K} \mathrm{~h}^{-1}$, maintained at $1273 \mathrm{~K}$ for $5 \mathrm{~h}$, and then cooled at the rate of $-100 \mathrm{~K} \mathrm{~h}^{-1}$. 
Rhodium cocatalyst was loaded on the surface of the NTO samples by a photodeposition method [19]. The NTO sample $(4 \mathrm{~g})$ dispersed in pure water $(360 \mathrm{~mL})$ in a beaker $(500 \mathrm{~mL})$ was photoirradiated from the upper side with a xenon lamp (PE300BUV) with magnetically stirring for $30 \mathrm{~min}$. After adding methanol $(40 \mathrm{~mL})$ as a reductant and small amount of an aqueous solution of rhodium chloride $\left(\mathrm{RhCl}_{3}\right)$, the mixture was stirred in the dark for $30 \mathrm{~min}$, followed by irradiation for $2 \mathrm{~h}$. The obtained powder sample was filtered with suction and dried at $323 \mathrm{~K}$ overnight. The loading amount of Rh as metal was 0.05 wt\%. The samples are referred to as Rh/NTO(x,y), e.g., Rh/NTO(50,-100).

\subsection{Characterizations}

Powder X-ray diffraction (XRD) pattern of the sample was recorded at room temperature on a Lab X XRD-6000 (Shimadzu) using Ni-filtered $\mathrm{Cu} K \alpha$ radiation $(40 \mathrm{kV}, 30 \mathrm{~mA}$ ). The average crystallite size was calculated according to Scherrer equation, where Si powder was used as a reference for the full width at half maximum (FWHM). Nitrogen adsorption measurement was conducted at $77 \mathrm{~K}$ by a Monosorb (Quantachrome) to calculate Brunauer-Emmett-Teller (BET) specific surface area of the sample. Field emission scanning electron microscopy (SEM) images were taken by a JSM-890 (JEOL), where the accelerating voltage was $5 \mathrm{kV}$. The average particle sizes (length and thickness) of the NTO crystals were calculated from the sizes of around fifty particles, which were measured by a scale on the SEM images. Rh K-edge XAFS (X-ray absorption fine structure) spectra were recorded at the AR-NW10A station [34] of KEK IMSS PF (Photon Factory, Institute of Materials Structure Science, High Energy Accelerator Research Organization, Japan) at room temperature with an $\mathrm{Si}(311)$ double crystal monochromator in a transmission mode for reference samples and in a fluorescence mode by using a Lytle detector [35] (100 mm ion chamber filled with krypton) with a ruthenium filter ( $\mu \mathrm{t}=3$ ) for the Rh/NTO samples. The spectra were analyzed with a REX 2000 software (Rigaku) to obtain XANES (X-ray absorption near edge structure), EXAFS (Extended $x$-ray absorption fine structure), and Fourier transformed EXAFS spectra. The range for the Fourier transform of EXAFS was $2.55-12.05 \AA^{-1}$ in wavenumber.

\subsection{Photocatalytic reaction tests}

Photocatalytic reaction tests for the PSRM were carried out with a fixed-bed flow reactor as described in our previous studies [10-19, 33]. The catalyst powder was pressed under $10 \mathrm{MPa}$ and ground into granules of 300-600 $\mu \mathrm{m}$. The catalyst granules were put into a quartz reactor $\left(50 \times 20 \times 1 \mathrm{~mm}^{3}\right)$, where the irradiation area was regulated to be 7.0 $\mathrm{cm}^{2}\left(35 \times 20 \mathrm{~mm}^{2}\right)$. The reaction gas mixture of $\mathrm{CH}_{4}(25 \%)$ and $\mathrm{H}_{2} \mathrm{O}(0.75 \%)$ with an argon carrier was introduced at a flow 
rate of $50 \mathrm{~mL} \mathrm{~min}{ }^{-1}$ without heating at atmospheric pressure in the dark for $30 \mathrm{~min}$. The catalyst cell was irradiated from the $300 \mathrm{~W}$ xenon lamp without using any optical filter, where the light intensity was $14 \mathrm{~mW} \mathrm{~cm}^{-1}$ measured in the range of $245 \pm 10 \mathrm{~nm}$. The temperature was measured to be around $323 \mathrm{~K}$. The outlet gas was analyzed by online gas chromatography with a thermal conductivity detector at an interval of ca. $30 \mathrm{~min}$. Since the sensitivity for $\mathrm{CO}_{2}$ in the argon carrier was low, the experimental error for the values of $\mathrm{CO}_{2}$ production rate was relatively large.

\section{Results and discussion}

\subsection{Characterization of the prepared sodium titanate samples}

Figure 1A shows XRD patterns of the Rh/NTO $(x, y)$ samples prepared with various solute concentration $(x)$ and cooling rate $(y)$. All the $\mathrm{Rh} / \mathrm{NTO}(x, y)$ samples showed the diffraction patterns assigned to $\mathrm{Na}_{2} \mathrm{Ti}_{6} \mathrm{O}_{13}$ phase (ICSD No. 23877) [36], and only the Rh/NTO(50,-10) sample showed a small diffraction at $10.48^{\circ}$ due to $\mathrm{Na}_{2} \mathrm{Ti}_{3} \mathrm{O}_{7}$ phase (ICSD No. 250000) [37]. It is reported that calcination at $1023 \mathrm{~K}$ for a long time in the solid state reaction method makes a phase transition from $\mathrm{Na}_{2} \mathrm{Ti}_{6} \mathrm{O}_{13}$ phase to $\mathrm{Na}_{2} \mathrm{Ti}_{3} \mathrm{O}_{7}$ phase [38], suggesting that the slower cooling rate such as $-10 \mathrm{~K} \mathrm{~h}^{-1}$ would give enough time for the phase transition at higher temperature. Figs. $1 \mathrm{~B}$ and $1 \mathrm{C}$ show enlarged XRD profiles at low angle range $\left(10^{\circ}-20^{\circ}\right)$ and high angle range $\left(48^{\circ}-50^{\circ}\right)$. The $\mathrm{Rh} / \mathrm{NTO}(5,-100)$ sample exhibited unassigned diffraction lines overlapping at the diffraction lines of $(200)$ at $12.0^{\circ}$ and $(-201)$ at $14.2^{\circ}$.

In these diffraction patterns, the distribution of the diffraction intensities seems different from sample to sample. The Rh/NTO samples prepared by the flux method showed larger diffraction lines of $(200)$ and $(-201)$ faces and smaller lines of (020) than the Rh/NTO $(100,-100)$ sample prepared by the SSR method, which means the characteristic isotropic crystal growth as shown later. It is generally considered that the $\mathrm{NaCl}$ flux would restrict the crystal growth of a certain direction to provide unique morphology of the crystals.

The average crystallite sizes were estimated from the FWHM of some diffraction lines by using Scherrer's equation. The intensity of the diffraction line of (020) were weak and the values calculated from them were larger than $0.2 \mu \mathrm{m}$ in the most cases, which are not available for the discussion of the detailed structures due to the limitation of this method [39]. The average crystallite size calculated from (200) at $12.0^{\circ}$, which is the largest diffraction line, were listed in Table 1 , except for the $\mathrm{Rh} / \mathrm{NTO}(5,-100)$ sample. With increasing the solute concentration $(x)$ among the $\mathrm{Rh} / \mathrm{NTO}(x,-100)$ samples, the average crystallite size increased (Table 1, entries 3 and 6), while among the Rh/NTO( $x,-10)$ samples, 
however, the average crystallite size decreased (Table 1, entries 2 and 5). Among the Rh/NTO(50,y) samples, no clear correlation was found between the cooling rate $(y)$ and the average crystallite size (Table 1, entries 2-4).
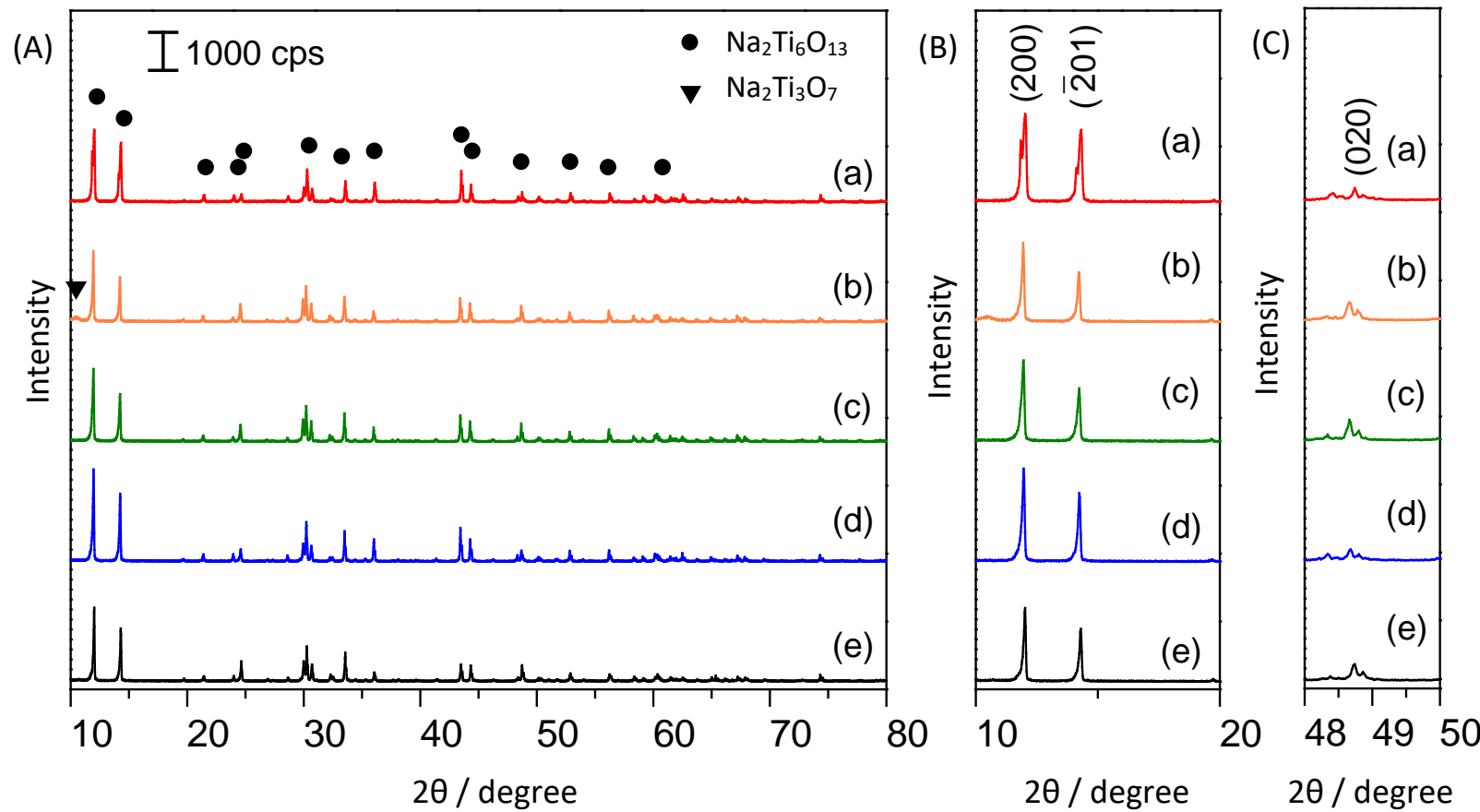

Fig. 1 XRD patterns of the representative $\operatorname{Rh} / \operatorname{NTO}(x, y)$ samples prepared at various conditions, (A) the overview, (B) the low angle range, and (C) the high angle range. The samples are (a) Rh/NTO(5,-100), (b) Rh/NTO(50,-10), (c) Rh/NTO(50,-100), (d) Rh/NTO(50,-120000), and (e) Rh/NTO(100,-100).

Table 1 Average crystallite size , particle size, aspect ratio, and specific surface area of the Rh/NTO samples.

\begin{tabular}{|c|c|c|c|c|c|c|c|}
\hline \multirow[t]{3}{*}{ Entry } & \multirow[t]{3}{*}{ Sample } & \multirow{3}{*}{$\begin{array}{l}\text { Crystallite size } \\
(\mathrm{XRD})^{a} / \mathrm{nm}\end{array}$} & \multicolumn{2}{|c|}{ Particle size $(\mathrm{SEM})^{b} / \mu \mathrm{m}$} & \multirow{3}{*}{$\begin{array}{l}\text { Aspect } \\
\text { ratio }^{c}\end{array}$} & \multirow{3}{*}{$\begin{array}{l}S_{\mathrm{SEM}}{ }^{d} \\
/ \mathrm{m}^{2} \mathrm{~g}^{-1}\end{array}$} & \multirow{3}{*}{$\begin{array}{l}S_{\mathrm{BET}} e \\
/ \mathrm{m}^{2} \mathrm{~g}^{-1}\end{array}$} \\
\hline & & & Length & Thickness & & & \\
\hline & & & (long side) & (short side) & & & \\
\hline 1 & Rh/NTO(5,-100) & - & 8.83 & 0.82 & 10.8 & 1.6 & 2.4 \\
\hline 2 & $\mathrm{Rh} / \mathrm{NTO}(50,-10)$ & 104 & 2.77 & 0.74 & 3.7 & 1.9 & 0.93 \\
\hline 3 & $\mathrm{Rh} / \mathrm{NTO}(50,-100)$ & 63.7 & 3.13 & 0.87 & 3.6 & 1.6 & 1.5 \\
\hline 4 & $\mathrm{Rh} / \mathrm{NTO}(50,-120000)$ & 89.8 & 3.00 & 0.83 & 3.6 & 1.7 & 1.7 \\
\hline 5 & $\mathrm{Rh} / \mathrm{NTO}(80,-10)$ & 77.6 & 1.70 & 0.99 & 1.7 & 1.5 & 1.0 \\
\hline 6 & $\mathrm{Rh} / \mathrm{NTO}(80,-100)$ & 128 & 2.22 & 1.04 & 2.1 & 1.4 & 1.2 \\
\hline 7 & $\mathrm{Rh} / \mathrm{NTO}(100,-100)$ & 114 & 2.16 & 1.35 & 1.6 & 1.1 & 0.75 \\
\hline
\end{tabular}




\footnotetext{
${ }^{a}$ Average crystallite size calculated from the FWHM of the diffraction line of (200) plane at $12.0^{\circ}$ in the XRD patterns.

${ }^{b}$ Average particle size calculated from the SEM images. ${ }^{c}$ Aspect ratio $=$ (the length)/(the thickness). ${ }^{d}$ Specific surface area estimated from the SEM images. ${ }^{e}$ Specific surface area calculated in the BET method.
}

SEM images of these samples are shown in Fig. 2. The samples prepared by the flux method showed the hexagonal rod-like structure with various sizes (Figs. $2 a, 2 b, 2 d$, and $2 e$ ), while the $R$ h/NTO $(100,-100)$ sample prepared in the SSR method exhibited irregular shaped particles (Fig. 2c). In the previous study, it was clarified that a rod-like $\mathrm{Na}_{2} \mathrm{Ti}_{6} \mathrm{O}_{13} \mathrm{Crystal}$ of similar size was not polycrystals but single crystals [22], implying that these rod-like crystals might be single crystals.

The average crystal size of the long and short sides, i.e., the length and thickness of the rod-like crystals, were measured on these SEM images and the calculated average values are listed in Table 1. These values were not consistent with the crystallite size estimated from XRD, which would originate from the limitation of these methods or some other reasons such as an incompleteness of the crystals. Based on the observed average crystal size, with the increase of the solute concentration, the length became shorter and the thickness became slightly thicker. Thus, the aspect ratio varied from 10.8 to 2.1 with the increase of the solute concentration, and the Rh/NTO $(100,-100)$ sample prepared by the SSR method without the flux showed the smallest aspect ratio 1.6 (Fig. 3A, and Table 1, entries 1, 3, 6, and 7). It was evidenced that the flux can regulate the morphology and the aspect ratio. On the other hand, the variation of the cooling rate could not vary the particle size (Fig. 3B, and Table 1, entries 2-4), meaning that the solute concentration is more crucial parameter for the control of the size and the aspect ratio of the rod-like structure of the $\mathrm{Na}_{2} \mathrm{Ti}_{6} \mathrm{O}_{13}$ crystals in the flux method than the cooling rate from the molten mixture. These trend is almost similar to, but slightly different from, the literature [22], where some conditions were different from the present study, such as heating rate $\left(200 \mathrm{~K} \mathrm{~h}^{-1}\right)$ and the holding time $(10 \mathrm{~h})$ at $1273 \mathrm{~K}$.

The specific surface areas of these crystals were geometrically and very roughly estimated from these average sizes of the crystals, the rod-like morphology, and the density of the material. The results are listed in Table 1 with the BET specific surface area. The roughly estimated specific surface area was similar to the BET specific surface area for each sample, which is consistent with the rod-like crystals are nonporous single crystals covered with some flat facets.

The BET specific surface area decreased with increasing the solute concentration among the Rh/NTO $(x,-100)$ samples (Table 1, entries 1, 3, and 6). With increasing the cooling rate, it increased (Table 1, entries 2-4). These results show that the specific surface area of the samples can be also controlled by changing these parameters in the flux method. 


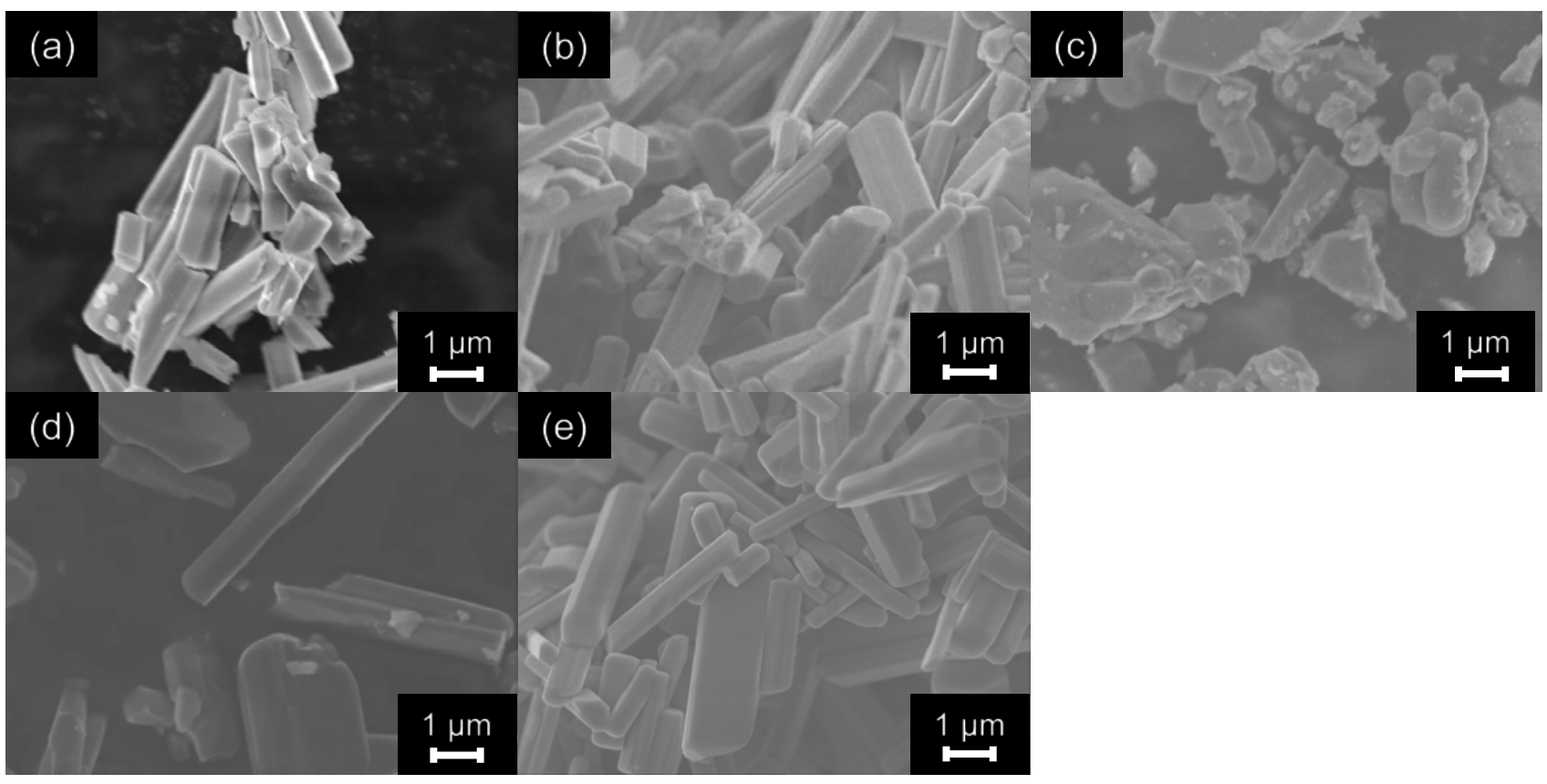

Fig. 2 SEM images of the representative Rh/NTO $(x,-100)$ samples prepared by the flux method with various solute concentration, $x$, of (a) 5, (b) 50, and (c) 100, where the Rh/NTO(100,-100) sample was prepared without the flux by the SSR method, and the Rh/NTO(50,y) samples prepared with various cooling rate , $y$, of (d) -10 and (e) $-120000 \mathrm{~K}$ $h^{-1}$.
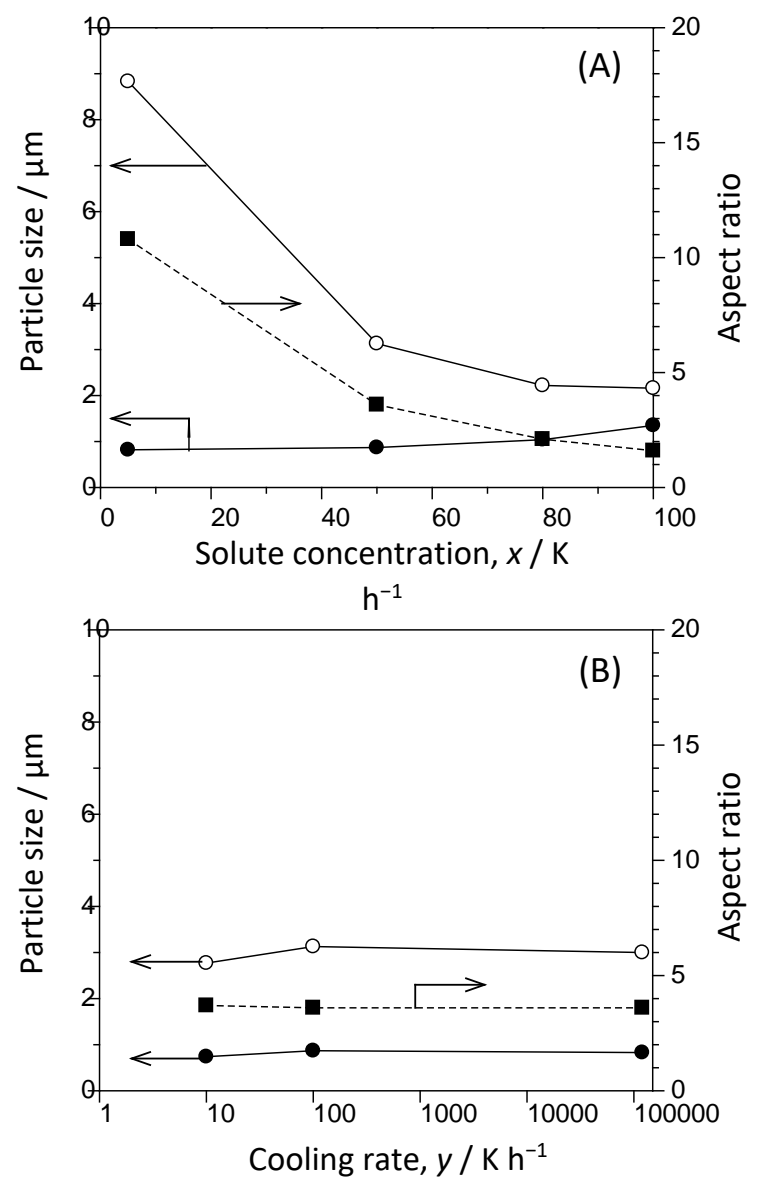

Fig. 3 The particle size and aspect ratio of the $\mathrm{Rh} / \mathrm{NTO}(x,-100)$ samples $(A)$ and the $\mathrm{Rh} / \mathrm{NTO}(50, y)$ samples (B). Open circles: the length, closed circles: the thickness, and closed squares: the aspect ratio. 


\subsection{Characterization of the loaded rhodium cocatalyst}

The Rh species loaded on the NTO samples were investigated by XAFS. Fig. 4 shows Rh K-edge XANES, EXAFS and Fourier transformed EXAFS spectra of the Rh/NTO(50,-100) and Rh/NTO(100,-100) samples before and after the photocatalytic reaction test and those of $\mathrm{Rh}_{2} \mathrm{O}_{3}$ powder and $\mathrm{Rh}$ foil as the reference samples. The absorption edge and the shape of the XANES spectra of the samples are almost similar to that of the bulk $\mathrm{Rh}_{2} \mathrm{O}_{3}$ reference sample (Fig. $4 \mathrm{~A}$ ), indicating that the Rh species loaded on the NTO surface are in the oxide state. But it is noted that the spectra of the $\mathrm{Rh} / \mathrm{NTO}$ samples showed a shoulder at higher energy side of the main peak, which feature is slightly different from the $\mathrm{Rh}_{2} \mathrm{O}_{3}$ sample, suggesting that the Rh oxide species were well dispersed on the NTO samples. It was also confirmed that the XANES spectra of the samples were not varied before and after the reaction test, suggesting that the state of the Rh cocatalyst unchanged during the PSRM.

EXAFS oscillations of the photocatalyst samples were similar to that of $\mathrm{Rh}_{2} \mathrm{O}_{3}$ at the lower $k$ range although those at higher $k$ range were less structured (Fig. 4B), which also suggests that the Rh oxide species on the NTO samples were well dispersed. The spectrum features before and after the photocatalytic reaction test were unchanged. In the Fourier transformed EXAFS for the bulk $\mathrm{Rh}_{2} \mathrm{O}_{3}$ (Fig. 4C, e), the peak at $1.6 \AA$ assignable to the first neighboring oxygen to the absorbing Rh atom, and the peaks at 2.4-2.6 ̊̊ assignable for the second neighboring Rh with different Rh-Rh distances were also observed, while for the Rh/NTO samples the peaks at 2.4-2.6 $\AA$ were not observed (Fig. 4C, a-d). This also supports that the Rh species are well dispersed on the NTO surface. In the literature [19], 0.1 wt\% of Rh oxide species loaded on the $\mathrm{K}_{2} \mathrm{Ti}_{6} \mathrm{O}_{13}$ surface, in which the $\mathrm{K}_{2} \mathrm{Ti}_{6} \mathrm{O}_{13}$ part was prepared by a solid state reaction method and $\mathrm{Rh}$ species was loaded by a photodeposition method, showed the peaks at longer distance range at 2.4-2.6 $\AA$, meaning that the present Rh species was well dispersed on the surface of the NTO crystals prepared by the flux method. 


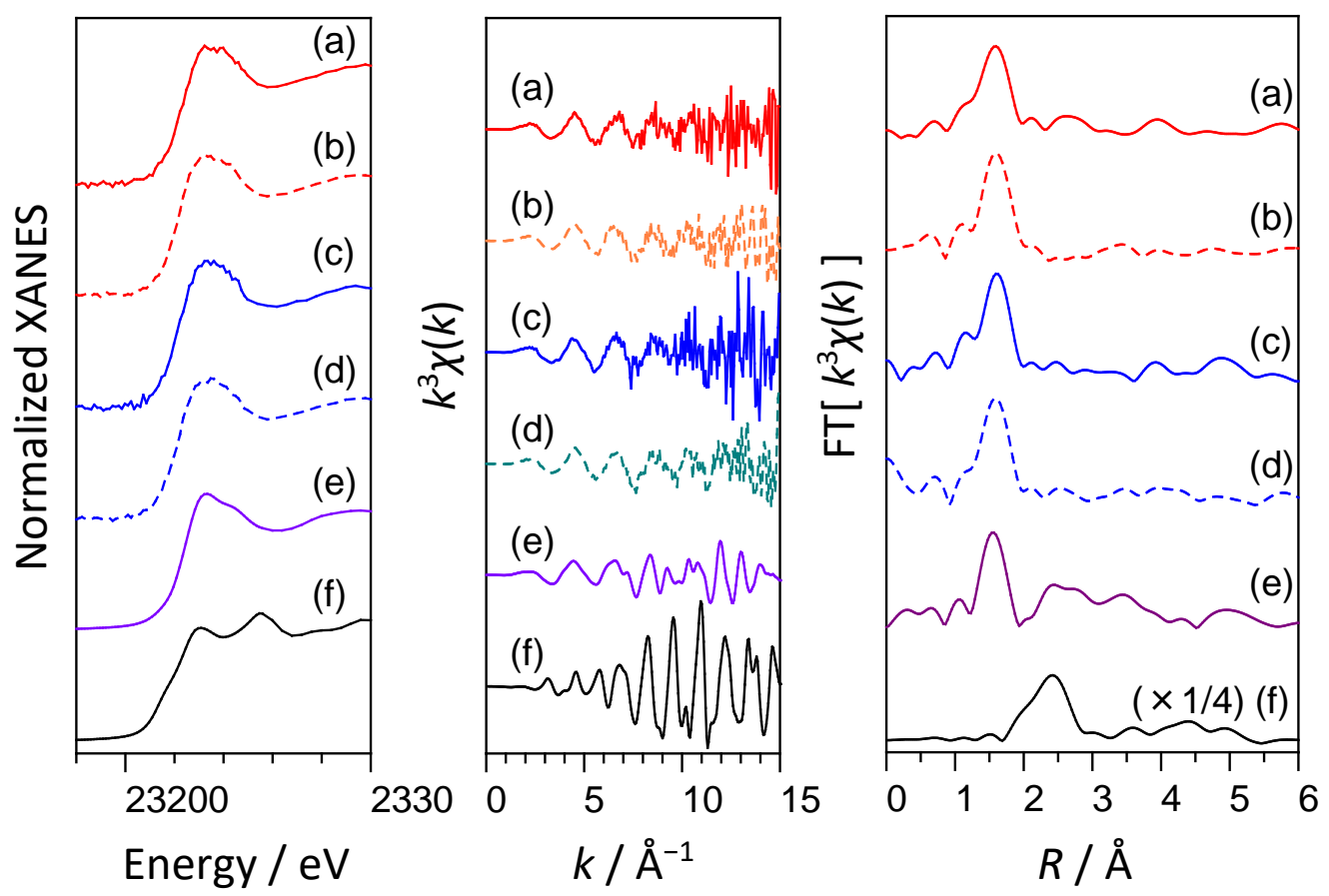

Fig. 4 Rh K-edge XANES (A), EXAFS (B), and Fourier transformed EXAFS (C) spectra of the Rh/NTO(50,-100) samples $(a, b)$ and the Rh/NTO $(100,-100)$ samples (c, d) before (a, c: solid lines) and after (b, d: broken lines) the photocatalytic reaction test, and those of $\mathrm{Rh}_{2} \mathrm{O}_{3}(e)$ and $\mathrm{Rh}$ foil ( $f$ ) as the reference samples.

\subsection{Photocatalytic activity}

The prepared Rh/NTO samples were examined for the photocatalytic steam reforming of methane (PSRM). Fig. 5 representatively shows a time course of the production rate of $\mathrm{H}_{2}$ and $\mathrm{CO}_{2}$ over the $\mathrm{Rh} / \mathrm{NTO}(50,-10)$ sample. The products observed were only $\mathrm{H}_{2}$ and $\mathrm{CO}_{2}$, and no other product such as $\mathrm{CO}$ was not detected. The production rates were constant with time, suggesting the reaction continuously proceeded. The production ratio of $\mathrm{H}_{2} / \mathrm{CO}_{2}$ was 3.9 at $4 \mathrm{~h}$ after the start of the photoirradiation, which is very close to the stoichiometric ratio of product in eq. 1 within the experimental error. In the dark, the products were not formed. These results clarified that the PSRM was photocatalytically promoted in the present conditions. Hereinafter, the photocatalytic activity was compared according to the production rate of $\mathrm{H}_{2}$, since it was more accurately determined than that of $\mathrm{CO}_{2}$ due to the analysis conditions. 


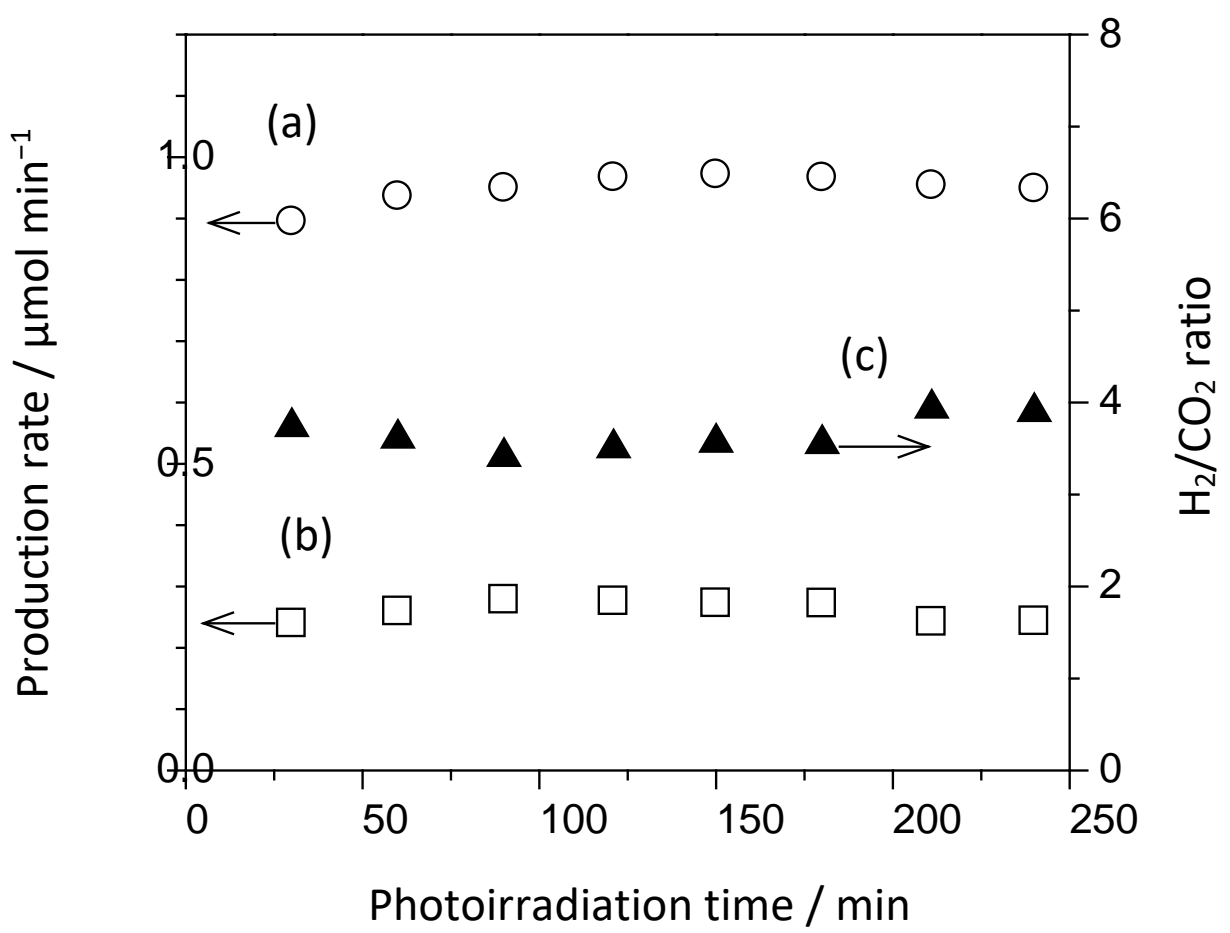

Fig. 5 Time course of the production rates of $\mathrm{H}_{2}(\mathrm{a})$ and $\mathrm{CO}_{2}(\mathrm{~b})$ and the production ratio of $\mathrm{H}_{2} / \mathrm{CO}_{2}(\mathrm{c})$ in the photocatalytic steam reforming of methane over the Rh/NTO $(50,-10)$ sample.

In the fixed-bed flow reactor, the irradiated surface of the photocatalyst powder would be considered to determine the photocatalytic reaction rate. To confirm this, the effect of the photocatalyst weight in the present quartz cell was investigated by using two samples, one is the Rh/NTO(50,-100) sample itself, another is the same sample diluted by quartz granules. Quartz granules are transparency for the irradiation light. Each sample was introduced into the quartz cell to occupy the same photoirradiation area $\left(7.0 \mathrm{~cm}^{2}\right)$. The results are shown in Table 2. The hydrogen production rate was almost the same for each sample, indicating that the photocatalytic reaction rate is determined by not the photocatalyst weight but the irradiation area. Thus, in the present study, not the catalyst weight but the photoirradiation area was regulated for every photocatalytic reaction test.

Table 2 Hydrogen production rates in the PSRM over the Rh/NTO $(50,-100)$ sample of different weight ${ }^{a}$

\begin{tabular}{llll}
\hline Entry & Samples & $\begin{array}{l}\text { Amount of photocatalysts }{ }^{b} \\
/ \mathrm{g}\end{array}$ & $\begin{array}{l}\mathrm{H}_{2} \text { production rate }^{c} \\
/ \mu \mathrm{mol} \mathrm{min}^{-1}\end{array}$ \\
\hline 1 & Rh/NTO(50,-100) & 0.74 & 0.58 \\
2 & Rh/NTO(50,-100) diluted by quartz granules & 0.50 & 0.56 \\
\hline
\end{tabular}

${ }^{a}$ The photocatalyst powder was filled in the cell so as to occupy the same area $\left(7.0 \mathrm{~cm}^{2}\right) .{ }^{b}$ Amount of the photocatalysts used for photocatalytic activity tests. ${ }^{c}$ The hydrogen production rate was evaluated at $5 \mathrm{~h}$ later from the start of photoirradiation. 
The effect of the Rh cocatalyst was confirmed by using the NTO(50,-120000) sample (Table 3). The activity of the Rh/NTO(50,-120000) sample was nine times higher than the bare NTO(50,-120000) sample. Since the same NTO sample was used in the same cell in this experiment and the cocatalyst was deposited without heating, the different photocatalytic activities clearly originated from not the properties of the $\mathrm{Na}_{2} \mathrm{Ti}_{6} \mathrm{O}_{13}$ crystals such as crystal size and specific surface area but the role of the deposited Rh cocatalyst such as the enhancement of the photoexcited electron-hole separation by the metal-semiconductor contact.

Table 3 Hydrogen production rates in the PSRM over the $\mathrm{Na}_{2} \mathrm{Ti}_{6} \mathrm{O}_{13}(50,-120000)$ samples with and without Rh cocatalyst loading ${ }^{a}$

\begin{tabular}{llll}
\hline Entry & $\begin{array}{l}\text { Loading amount of Rh } \\
(w t \%)\end{array}$ & $\begin{array}{l}\text { Amount of photocatalysts }{ }^{b} \\
/ \mathrm{g}\end{array}$ & $\begin{array}{l}\mathrm{H}_{2} \text { production rate }^{c} \\
/ \mu \operatorname{mol~min}^{-1}\end{array}$ \\
\hline 1 & 0 & 0.751 & 0.09 \\
2 & 0.05 & 0.715 & 0.82
\end{tabular}

\footnotetext{
${ }^{a}$ The photocatalyst powder was filled in the cell so as to occupy the same area $\left(7.0 \mathrm{~cm}^{2}\right) .{ }^{b}$ Amount of the photocatalysts used for photocatalytic activity tests. ${ }^{c}$ The hydrogen production rate was evaluated at $2.5 \mathrm{~h}$ later from the start of photoirradiation.
}

\begin{tabular}{llll}
\hline \multicolumn{3}{l}{ Table 4 Hydrogen production rates in the PSRM over the Rh/NTO samples ${ }^{a}$} \\
\hline Entry & Sample & $\begin{array}{l}\text { Amount of photocatalysts }{ }^{a} \\
\text { /g }\end{array}$ & $\begin{array}{l}\mathrm{H}_{2} \text { production rate }^{b} \\
/ \mu \mathrm{mol} \mathrm{min}^{-1}\end{array}$ \\
\hline 1 & Rh/NTO(5,-100) & 0.546 & 0.48 \\
2 & Rh/NTO(50,-10) & 0.962 & 0.96 \\
3 & Rh/NTO(50,-100) & 0.740 & 0.58 \\
4 & Rh/NTO(50,-120000) & 0.714 & 0.79 \\
5 & Rh/NTO(80,-10) & 0.925 & 0.70 \\
6 & Rh/NTO(80,-100) & 0.772 & 0.58 \\
7 & Rh/NTO $(100,-100)$ & 1.20 & 0.85
\end{tabular}

${ }^{a}$ The photocatalyst powder was filled in the cell so as to occupy the same area $\left(7.0 \mathrm{~cm}^{2}\right) .{ }^{b}$ Amount of the photocatalysts used for photocatalytic activity tests. ${ }^{c}$ The hydrogen production rate was evaluated at $5 \mathrm{~h}$ later from the start of photoirradiation.

Table 4 shows the results of the photocatalytic reaction tests over the Rh/NTO samples. Among the samples, the $\mathrm{Rh} / \mathrm{NTO}(50,-10)$ sample exhibited the highest activity for the PSRM, $0.96 \mu \mathrm{mol} \mathrm{min}{ }^{-1}$ of the $\mathrm{H}_{2}$ production rate in this 
conditions (Table 4, entry 2), which showed higher activity than the sample prepared by the SSR method (Table 4, entry 7).

Although the exact comparison is not possible due to the different reaction conditions, the present $\mathrm{Rh} / \mathrm{NTO}(50,-10)$ sample gave a higher hydrogen production than the reported photocatalysts such as $\mathrm{Pt} / \mathrm{TiO}_{2}[10,11], \mathrm{Pt} / \mathrm{CaTiO} 3[13,14]$, and $\mathrm{Pt} / \mathrm{Ga}_{2} \mathrm{O}_{3}[15,16]$, and a moderately high activity among the reported our photocatalysts $[10-19,33]$.

\subsection{Relation between the structure and the photocatalytic activity}

Among the $\mathrm{Rh} / \mathrm{NTO}(x,-100)$ samples, the photocatalytic activity slightly increased with the increase of the solute concentration $(x)$ and the Rh/NTO $(100,-100)$ sample prepared by the SSR method without the flux exhibited the highest activity among these samples (Table 4, entries $1,3,6$, and 7 ). From the results shown in Fig. $3 \mathrm{~A}$, the low solute concentration provided the larger particle size and aspect ratio. It is suggested that the smaller particle size and smaller aspect ratio gave higher photocatalytic activity among these samples.

On the other hand, among the $\mathrm{Rh} / \mathrm{NTO}(50, y)$ samples, no clear correlation was found between the cooling rate ( $y$ ) and the photocatalytic activity (Table 4, entries 2-4). When all the samples were considered, the aspect ratio does not show a clear relationship with the photocatalytic activity. Among the structural properties such as average crystallite size, average crystal size, and BET specific surface area (Table 1), it was found that the crystallite size correlated to the photocatalytic activity (Fig. 6), while no clear correlation was found on the other parameters. As shown in Fig. 6, the hydrogen production rate increased with the increase of the crystallite size to reach the maximum around $100 \mathrm{~nm}$ before decreasing.

In the previous studies for the PSRM with $\mathrm{Pt} / \mathrm{NaTaO}_{3}: \mathrm{La}$ photocatalyst, the trend that the photocatalytic activity increased with increasing crystallite size was found [33]. Similar positive effect of the crystallite size on the photocatalytic activity has been reported in some other heterogeneous photocatalytic reaction systems, such as photocatalytic reduction of $\mathrm{CO}_{2}$ with water [22,25], and photocatalytic $\mathrm{O}_{2}$ evolution from an aqueous $\mathrm{Ag}$ solution $[40,41]$. Amamo et al. reported that the larger particles, i.e., smaller surface area, of $\mathrm{WO}_{3}$ photocatalyst has higher photocatalytic activity since the recombination of the photoexcited electron and hole on the surface takes place faster than that in the bulk [40]. In the present study, larger crystallite size of the NTO crystals would have less amount of defects so as to realize the high activity. Another possibility is that the larger size of crystallite could receive many photons at the same time, which would be advantage for the photocatalytic reaction requiring multiple electrons and holes. 
The two samples having the larger crystallites than $100 \mathrm{~nm}$ were the $\mathrm{Rh} / \mathrm{NTO}(100,-100)$ sample prepared by the SSR method and the Rh/NTO(80,-100) sample prepared by small amount of the $\mathrm{NaCl}$ flux, both of which were of low aspect ratio such as 1.6 and 2.1. In these samples the influence of the $\mathrm{NaCl}$ flux was not or less expected on the crystal structure. The morphologies of these crystals were different from the long hexagonal rod-like structured crystals. These might be the reason why the lower $\mathrm{H}_{2}$ production rate was obtained than that expected from the larger crystallite size.

It is concluded that the Rh-loaded NTO crystals having larger crystallite size with the hexagonal rod-like structure prepared by the flux method can exhibit higher photocatalytic activity in the PSRM in the present conditions.

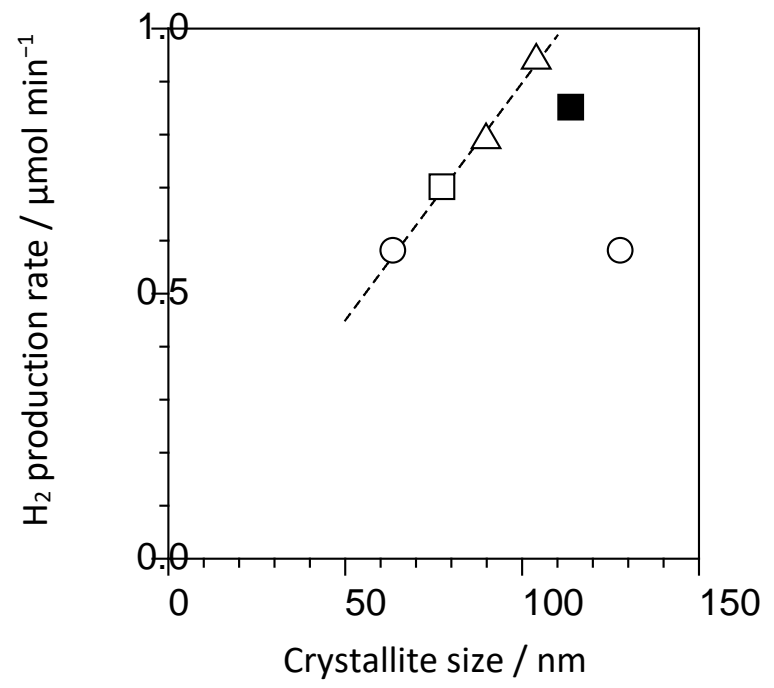

Fig. 6 Correlation between the hydrogen production rate in the PSRM and the crystallite size of the Rh/NTO photocatalysts. Open circles: the $\mathrm{Rh} / \mathrm{Na}_{2} \mathrm{Ti}_{6} \mathrm{O}_{13}(x,-100)$ photocatalysts prepared with various solute concentrations, open triangles: the $\mathrm{Rh} / \mathrm{Na}_{2} \mathrm{Ti}_{6} \mathrm{O}_{13}(50, c)$ photocatalysts with various cooling rate $(c=-10$ and -120000), open square: the $\mathrm{Rh} / \mathrm{Na}_{2} \mathrm{Ti}_{6} \mathrm{O}_{13}(80,-10)$ photocatalysts, and a closed square: the $\mathrm{Rh} / \mathrm{Na}_{2} \mathrm{Ti}_{6} \mathrm{O}_{13}(100,-100)$ photocatalysts prepared without the flux. The hydrogen production rate was evaluated at $5 \mathrm{~h}$ later from the start of photoirradiation. The value of the Rh/NTO(5,-100) sample was not plotted here since it could not give a precise crystallites size.

\subsection{Reaction mechanism}

In the present study, the reaction photocatalytically took place according to the eq. 1 to give both $\mathrm{H}_{2}$ and $\mathrm{CO}_{2}$ with the expected mol ratio $\left(\mathrm{H}_{2} / \mathrm{CO}_{2}=4\right)$ almost constantly and the components of the Rh/NTO photocatalyst is similar to the reported $\mathrm{Pt} / \mathrm{TiO}_{2}$ photocatalyst consisting of semiconductor metal oxide and deposited cocatalyst [11]. It is also demonstrated that the Rh cocatalyst function as an electron receiver to enhance the photocatalytic activity, suggesting 
that the reductive reaction occurs on the Rh cocatalyst and the oxidative reaction proceeds on the surface of the $\mathrm{Na}_{2} \mathrm{Ti}_{6} \mathrm{O}_{13}$ crystals.

Thus, although the reaction mechanism was not investigated in the present study, the reaction mechanism would be proposed in the similar way to the one in the previous paper [11] as follows: Both methane and water are activated by photogenerated holes to give surface intermediates and protons on the surface of the $\mathrm{Na}_{2} \mathrm{Ti}_{6} \mathrm{O}_{13}$ crystals, the intermediates react with water and holes to form $\mathrm{CO}_{2}$ and protons, and the protons are reduced by the photoexcited electrons to generate $\mathrm{H}_{2}$ on the Rh cocatalyst sites.

\section{Conclusions}

In the present study, the $\mathrm{Na}_{2} \mathrm{Ti}_{6} \mathrm{O}_{13}$ (NTO) crystals were prepared by the flux method, followed by the loading of the well dispersed rhodium oxide cocatalyst. The solute concentration in the molten mixture much affected the structure of the NTO crystals such as the crystallite size, the aspect ratio of the rod-like structure, and the specific surface area. The Rh/NTO photocatalysts constantly convert methane and water to produced hydrogen and carbon dioxide in the photocatalytic steam reforming of methane (PSRM). The photocatalysts having various structure exhibited various activities in the PSRM. It was found that the Rh-loaded NTO crystals having larger crystallite size with the hexagonal rodlike structure prepared by the flux method can exhibit higher photocatalytic activity in the PSRM in the present conditions. Further optimization of the preparation conditions in the flux method and the property and loading amount of cocatalyst would contribute to the development of the $\mathrm{Na}_{2} \mathrm{Ti}_{6} \mathrm{O}_{13}$ crystal photocatalysts.

\section{Acknowledgements}

The XAFS experiments were performed under the approval of the Photon Factory Program Advisory Committee (proposal no. 2014G547). This work was financially supported by a Grant-in-Aid for Scientific Research (B), (No. 25289285), and a Grant-in-Aid for Scientific Research on Innovative Areas "Artificial photosynthesis (AnApple)" (No. 25107515) from JSPS, and the Program for Element Strategy Initiative for Catalysts \& Batteries (ESICB), commissioned by the MEXT of Japan.

\section{References}


[1] J. R. Rostrup-Nielsen, Catal. Today 18 (1993) 305-324.

[2] M. A. Peña, J. P. Gómez, J. L. G. Fierro, Appl. Catal. A 144 (1996) 7-57.

[3] J. N. Armor, Appl. Catal. A 176 (1999) 159-176.

[4] A. Kudo, Y. Miseki, Chem. Soc. Rev. 38 (2009) 253-278.

[5] K. Maeda, K. Domen, J. Phys. Chem. Lett. 1 (2010) 2655-2661.

[6] L. Yuliati, H. Yoshida, Chem. Soc. Rev. 37 (2008) 1592-1602.

[7] K. Shimura, H. Yoshida, Energy Environ. Sci., 4 (2011) 2467-2481.

[8] K. Shimura, H. Yoshida, Catal. Surv. Asia 18 (2014) 24-33.

[9] J. Baltrusaitis, I. Jansen, J.D. Schuttlefield Christus, Catal. Sci. Technol. 4 (2014)2397-2411.

[10] H. Yoshida, S. Kato, K. Hirao, J. Nishimoto, T. Hattori, Chem. Lett. 36 (2007)430-431.

[11] H. Yoshida, K. Hirao, J. Nishimoto, K. Shimura, S. Kato, H. Itoh, T. Hattori, J. Phys. Chem. C, 112 (2008) $5542-$ 5551.

[12] K. Shimura, S. Kato, T. Yoshida, H. Itoh, T. Hattori, H. Yoshida, J. Phys. Chem. C, 114 (2010) 3493-3503.

[13] K. Shimura, H. Yoshida, Energy Environ. Sci., 3 (2010) 615-617.

[14] K. Shimura, H. Miyanaga, H. Yoshida, Stud. Surf. Sci. Catal., 175 (2010) 85-92.

[15] K. Shimura, T. Yoshida, H. Yoshida, J. Phys. Chem. C, 114 (2010) 11466-11474.

[16] K. Shimura, K. Maeda, H. Yoshida, J. Phys. Chem. C, 115 (2011) 9041-9047.

[17] K. Shimura, H. Yoshida, Phys. Chem. Chem. Phys., 14 (2012) 2678-2684.

[18] K. Shimura, H. Kawai, T. Yoshida, H. Yoshida, Chem. Commun., 47 (2011) 8958-8960.

[19] K. Shimura, H. Kawai, T. Yoshida, H. Yoshida, ACS Catal., 2 (2012) 2126-2134.

[20] C.Y. Xu, J. Wu, P. Zhang, S.P. Hu, J.X. Cui, Z.Q. Wang, Y.D. Huang, L. Zhen, CrystEngComm 15 (2013) 3448-3454.

[21] K. Teshima, K. Yubuta, S. Sugiura, T. Suzuki, T. Shishido, S. Oishi, Bull. Chem. Soc. Jpn. 79 (2006) 1725-1728.

[22] H. Yoshida, M. Sato, N. Fukuo, L. Zhang, T. Yoshida, Y. Yamamoto, T. Morikawa, T. Kajino, M. Sakano, T. Sekito, S. Matsumoto, H. Hirata, Catal. Taday, 303 (2018) 296-304.

[23] S. Suzuki, K. Teshima, M. Kiyohara, H. Kamikawa, K. Yubuta, T. Shishido, S. Oishi, CrystEngComm 14 (2012) 4176-4180.

[24] H. Yoshida, M. Takeuchi, M. Sato, L. Zhang, T. Teshima, M.G. Chaskar, Catal. Today 232 (2014) $158-164$.

[25] H. Yoshida, L. Zhang, M. Sato, T. Morikawa, T. Kajino, T. Sekito, S. Matsumoto, H. Hirata, Catal. Today 251 (2015) 132-139. 
[26] A. Anzai, N. Fukuo, A. Yamamoto, H. Yoshida, Catal. Commun. 100 (2017) 134-138.

[27] H. Kato, M. Kobayashi, M. Hara, M. Kakihana, Catal. Sci. Technol. 3 (2013) 1733-1738.

[28] D. Arney, T. Watkins, P.A. Maggard, J. Am. Ceram. Soc. 94 (2011) 1483-1489.

[29] D. Arney, B. Porter, B. Greve, P.A. Maggard, J. Photochem. Photobiol. 199 (2008) 230-235.

[30] Q. Wang, T. Hisatomi, Y. Moriya, K. Maeda, K. Domen, Catal. Sci. Technol. 3 (2013) 2098-2103.

[31] Y. Miseki, K. Saito, A. Kudo, Chem. Lett. 38 (2009) 180-181.

[32] Y. Hosogi, H. Kato, A. Kudo, J. Mater. Chem. 18 (2008) 647-653.

[33] A. Yamamoto, S. Mizuba, Y. Saeki, H. Yoshida, Appl. Catal. A, 521 (2016) 125-132.

[34] M. Nomura, Y. Koike, M. Sato, A. Koyama, Y. Inada, K. Asakura, AIP Conf. Proc. 882 (2007) 896-898.

[35] F. W. Lytle, R. B. Greegor, D. R. Sandstorm, E. C. Marques, J. Wong, C. L. Spiro, G. P. Huffman, F. E. Huggins, Nucl. Instrum. Methods Phys. Res., Sect. A 226 (1984) 542-548.

[36] S. Andersson, A. D. Wadsley, Acta Crystallogr. 15 (1962) 194-201.

[37] O. V. Yakubovich, V. V. Kireev, Kristallografiya,48 (2003) 29-33.

[38] J. Yang, D. Li, X. Wang, X. Yang, L. Lu, J. Mater. Sci. 38 (2003) 2907-2911.

[39] U. Holzwarth, N. Gibson, Nat. Nanotech. 6 (2011) 534-534.

[40] F. Amano, E. Ishinaga, A. Yamakata, J. Phys. Chem. C 117 (2013) 22584-22590.

[41] F. Amano, M. Nakata, Appl. Catal. B 158-159 (2014) 202-208. 